\title{
Behavior of Concrete Utilizing Recycled Aggregate - A Review
}

\author{
Ashish Shrimali*, Digvijay S. Chauhan**, Dr. Trilok Gupta*** and \\ Dr. Ravi K. Sharma**** \\ * (M.Tech student, Department of Civil Engineering, College of Technology and Engineering, MPUAT, \\ Udaipur) \\ **(Research Fellow, Department of Civil Engineering, College of Technology and Engineering, MPUAT, \\ Udaipur) \\ *** (Assistant Professor, Department of Civil Engineering, College of Technology and Engineering, MPUAT, \\ Udaipur) \\ **** (Professor, Department of Civil Engineering, College of Technology and Engineering, MPUAT, Udaipur)
}

\begin{abstract}
Today's modern era is demanding more and more infrastructure development and with the increasing demand of infrastructure, the demand and supply chain of the construction material are getting affected. With increasing pace of development, a great concern is required towards environment as well as natural resources. In this paper, behavior of concrete utilizing recycled aggregate is critically reviewed. Properties of recycled aggregate are discussed at first, followed by the properties of concrete utilizing recycled aggregate. It has been reported that recycled aggregate was found useful if the replacement level is about $30 \%$. This type of concrete has been used in many applications. Recycled aggregate can be seen as future material which will be eco -friendly and will decrease in project cost.
\end{abstract}

Keywords: Recycled aggregate, concrete utilizing recycled aggregate, construction and demolition waste.

\section{INTRODUCTION}

Concrete plays a essential role in infrastructure development having main ingredient as cement, aggregates (course and fine) \& water and among these ingredients, aggregate occupy the largest volume of about $60-75 \%$ of total concrete volume [1]. Construction industry uses approximately 20 billion tons of raw materials annually as reported [2]. It consumes a large amount of natural resources that cause substantial environmental, energy and economic losses as it exploits $50 \%$ raw material, $40 \%$ of total energy, as well as generates $50 \%$ of total waste [2]. The depletion of good quality aggregates along with the increase in aggregate requirement due to increasing infrastructure development makes the lesser availability of natural materials, over quarrying led direct impact on environment and demand-supply chain of construction material are getting affected. With increasing pace of development a great concern is required towards environment as well as natural resources so alternative material is required to reduce the depletion of natural resources with keeping great care of environmental issues.

Recycled aggregate are obtained from demolished waste concrete after recycling process and used as a part of production of fresh concrete. They are obtained from waste concrete, rejected precast concrete members, broken masonry, laboratory sample waste, concrete road beds and asphalt pavement, leftover concrete from ready mix concrete plant and the waste generated from different laboratories [6]. Further recycling process is applied on the collected concrete waste, in this process of obtaining recycled aggregate concrete waste, jaw crushers are mainly used for primary crushing, followed by secondary crusher, named as Impact crushers, it produces a better quality of aggregate with less adhered mortar content [9]. The selection of crushers at various stages depends on several factors such as maximum grain size, desired output quality, desirable particle size and shape of the various fractions, and amount of fines produced. Higher quality aggregates can be obtained by involving some more process like sorting, screening and removal of contaminant etc [6]. Mobile crushers are being employed in today's world as to decrease the transportation cost as well as time [2]. Major concrete waste part is coming from demolition of old building as those old buildings have either completed their age or are no longer of purpose fulfilling, in this way they produce a large waste, which earlier was used as land feeling material, but now due to shortage of land, dumping issue has been created, which is leading towards land debaris and other environmental problems too.

In this paper, behavior of concrete utilizing recycled aggregate is critically reviewed. Properties of recycled aggregate are discussed at first, followed by the properties of concrete utilizing recycled 
aggregate. This type of concrete has been used in many applications, so salient case studies have also been reviewed. In the end concluding remarks have been reported which will be helpful for the future research progress in this field.

\section{PROPERTIES OF RECYCLED AGGREGATE}

Recycled aggregate, obtained from construction and demolition waste generally consists of natural coarse aggregate and adhered mortar. The old mortar mostly contains fine aggregate, hydrated and un-hydrated cement particles. The quality of recycled aggregate mostly depends on the methods of recycling process to be adopted, but the properties of recycled aggregate mainly depend on the properties of concrete from where recycled aggregate were obtained and water-cement ratio of the original concrete from which it was obtained $[12,13]$. The dry mortar coating over recycled aggregate makes it porous, inhomogeneous and less dense $[3,10]$. Many studies reported that coating in recycled aggregate varies from $25 \%$ to $60 \%$ by volume and according to the size of aggregate as with increase in size the surface area increases $[12,17,15]$. It can be noticed through a number of studies that the coating of mortar on recycled aggregate directly increases the water absorption capacity of concrete [18], as it generates porous nature which is responsible for the higher water absorption capacity of recycled aggregate as these pores absorbing more water [22]. The water absorption capacity is 2-3 times higher of recycled aggregate as compared to natural aggregate $[11,14]$. Poon et al. [15], experimentally investigated that it may vary up to $15 \%$. It varies depending on the amount of cement paste attached to the surface of the aggregate [24].

The density and specific gravity of the attached mortar is quite less and accounts for the low specific gravity, bulk density and saturated surface dry density of recycled aggregate [17,19]. As on crusher the practical size can't be uniformly maintained, so they are poorly graded [21]. Recycled aggregate are round in size which also decreases the properties of concrete utilizing recycled aggregate, as due to round size the bonding between concrete become loose and sometime its noticed in microstructure that crack is produced between aggregate and old mortar which segregate the aggregate with rest of concrete and leads to decrease in strength such as crushing strength, impact resistance and abrasion resistance when compared to natural aggregate $[13,26]$.

\section{CONCRETE UTILIZING RECYCLED AGGREGATE}

Recycled aggregate have been used to prepare the concrete by partial or full replacement of natural aggregate. In literature various experimental studies have been carried out on this type of concrete. Various properties such as workability, compression, tension, creep-shrinkage, modulus of elasticity and durability properties as water permeability and ultrasonic pulse velocity are discussed below:

\subsection{Properties of fresh concrete utilizing recycled aggregate}

Workability is highly affected by water cement ratio of concrete, size of aggregate used, shape of concrete and ration of fine to coarser aggregate used in concrete, a workable concrete should never bleed or show segregation. Many studies reported that desired workability is hard to achieve in case of concrete utilizing recycled aggregate [28,29,30]. As the mortar coating does more water absorption so high water-cement ratio is required to maintain the desired workability [31]. Some researchers also concluded that at least $10 \%$ extra water is required in case of recycled aggregate as compared to quarried aggregate [32], therefore water-cement ratio gets disturbed and water required for workability, gets absorbed by recycled aggregate [33].

Etxeberria et al., [9] reported the solution to high water absorption and alteration in water cement ratio was use of pre-soaked recycled aggregate [9]. On the other hand it was reported that the workability is also directly influenced by the properties of parent concrete as with the better quality of parent concrete the bond development of recycled aggregate and rest ingredients is increased $[26,27,34]$. On the other hand it was reported by Tavakali et al., [23] that the slump loss of recycled aggregate concrete can be overcome with incorporation of many admixtures, super plasticizer and minerals.

\subsection{Properties of hardened concrete utilizing recycled aggregate}

On hardened concrete compressive, tensile, creep-shrinkage, modulus of elasticity have been observed and reported below:

\subsubsection{Compressive strength}

Compressive strength is highly affected by parameters like water-cement ratio of concrete, with the increase in water cement ration the strength goes down and in case of recycled aggregate it also gets influenced by the percentage of replacement of recycled aggregate with quarried aggregate in 
concrete also in the case when compared with same water-cement ratio $[21,38,39]$. It was reported that reduction in strength is mostly in between $12 \%$ to $30 \%$ but sometimes till $60 \%$ with $100 \%$ replacement of recycled aggregate $[7,9,18,19]$. Sometimes the strength parameter get influenced by un-hydrated coating of parent concrete over recycled aggregate as due to the curing condition may unable to complete the hydration process in parent concrete [11]. In an study it was reported that when the water cement ratio of parent concrete is kept equal or lower than the old parent concrete than the strength obtained at $100 \%$ replacement level of recycled aggregate is equal or may be more [11]. However, Ridzuan et al., [33] reported an increase in compressive strength of recycled aggregate concrete as compare to conventional concrete. It may be due to the ignorance of parent concrete properties or may be due to use of high quality recycled aggregate as their water absorption may be less and the remaining water in turn increased the water-cement ratio, as when high water cement ratio $0.40,0.55$ and 0.70 for recycled aggregate concrete was studied the result was increase in compressive strength of recycled aggregate concrete as compared to conventional concrete [40]. While number of studies shows that recycled aggregate can be used up to $30 \%$ replacement level by volume to maintain equal compressive strength as of conventional concrete $[4,39]$.

\subsubsection{Tensile strength}

Flexure strength: - Studies reported maximum $10 \%$ to $24 \%$ reduction in flexure strength has been reported when different level of recycled aggregate is used to produce concrete $[7,19,31,23]$. When compared to normal concrete different water cement ratio was investigated than a considerable difference in the flexural strength has been reported [34]. As the recycled aggregate replacement ratio increases, the flexure strength decreases [30].

Split tensile strength: - It has been reported that recycled aggregate concrete exhibit better $[9,43]$ or similar [21] strength parameter as compared to conventional concrete. Explanation may be as concluded by study which reported that due to high water absorption capacity of recycled aggregate a better bond is developed in concrete between recycled aggregate and binder which results in increased split tensile strength [9]. By replacing recycled aggregate up to $100 \%$ from quarried aggregate in concrete divergence has been reported in the split tensile strength [43].

\subsubsection{Creep}

Creep deformation is usually influenced by aggregate and mix proportion of concrete with age of concrete. In case of recycled aggregate concrete it can be noticed that it increases with increasing proportion of replacement level of recycled aggregate in concrete and also directly affected by the content and properties of paste, $50 \%$ higher creep is reported in recycled aggregate concrete as compared to normal concrete $[14,41]$. On the other hand reports are also stated that creep was crossing $50 \%$ when $100 \%$ replacement level of recycled aggregate [41]. However the consequences of higher creep can also be stopped by partially replacing or extra adding minerals with the binder [38]

\subsubsection{Shrinkage}

Changes of pore water content due to drying or wetting processes cause significant volume changes of concrete in load-free specimens. As the recycled aggregate absorb more water which lead to decrease in pore water pressure in concrete which develops more shrinkage cracks as compared to fresh quarried aggregate [19]. It has been reported that the shrinkage may be due to higher stiffness of recycled aggregate [19] and on the other hand shrinkage also increases with the increase in recycled aggregate content in concrete [35]. On the other hand some study reported that the coating of mortar on recycled aggregate leads to increased shrinkage as compared to conventional aggregate $[5,8,23]$. Shrinkage is noticed to be $20 \%$ increased when $50 \%$ replacement of natural aggregate was done and when $100 \%$ replacement was done than it got increased to $70 \%$ in a period of six months [20,14,28,41]. However, if $30 \%$ partial replacement of recycled aggregate used in concrete than shrinkage can be as normal as of normal concrete [21] and shrinkage increases with increase in recycled aggregate replacement content as reported by investigation [5]. Many study also reported that the effect of shrinkage can be minimized by incorporating some minerals and admixtures in recycled aggregate concrete [27,38,39].

\subsubsection{Modulus of elasticity}

It is directly affected by the transition zone properties, dense nature of porosity of aggregate. In various investigation it was reported that with the increase in partial replacement of recycle aggregate the modulus of elasticity decreases [4,31]. Some Experimental studies reveled a decrease of 20to $25 \%$ [44] and some of $39 \%$ [30] while other reported decrease up to $45 \%$ when $100 \%$ recycled aggregate were replaced with quarried aggregate [4,18,25,37]. Studies reported that due to coating of mortar over recycled aggregate the modulus of elasticity decreases [39]. However if replacement level of recycled aggregate is kept only $30 \%$ then the reduction in modulus of elasticity was observed 
only35\% [45] and it can be concluded with investigation that the decrease in modulus of elasticity is due to reduction in stiffness of concrete [16].

\subsection{Durability properties of concrete utilizing recycled aggregate}

Durability is one of the important requirement to judge the life of concrete, water permeability and ultrasonic pulse velocity are reported to study the durability behavior of concrete utilizing recycled aggregate as below:

\subsubsection{Water Permeability}

Water permeability has reported higher for recycled aggregate concrete as compared to conventional concrete [47], While it was also noticed that concrete mixture with w/c ratio of 0.4 have the lowest in water permeability, compared to the result 0.5 and $0.6 \mathrm{w} / \mathrm{c}$ ratio mixes [47].

\subsubsection{Ultrasonic Pulse velocity}

Ultrasonic pulse velocity increases with the age of concrete from 7 days to 28 days [46]. The rate of increment of Pulse Velocity decreases gradually from 28 days to 56 days [46]. At the same time, for normal concrete the ultrasonic pulse velocity results are more, as compared to recycled aggregate because of the cement paste attached to the recycled aggregate [46]. Also, the water absorption and bulk density of recycled aggregate are more as compared to normal aggregate. Therefore, the results of $50 \%$ replacement are less as compared to $25 \%$ replacement case and the results of $25 \%$ replacement are less as compared to normal concrete [46].

\section{CASE STUDIES}

Concrete utilizing recycled aggregate has been used for many applications. Some salient studies are reported below:

4.1 Case Study I:- Influence of recycled coarse aggregate on mechanical and durability properties of concrete [48].

This case study was performed to evaluate the mechanical properties and durability properties for concrete utilizing recycled aggregate. In this study five different mixes were prepared by replacing the coarse aggregate by the recycled aggregate at varied replacement level $(0 \%, 15 \%$, $30 \%, 60 \%$ and $80 \%$ ). Control specimen was denoted as $0 \%$ of the recycled aggregate replacement. Compressive strength, shrinkage tests and ultrasonic pulse velocity were performed on prepared samples.

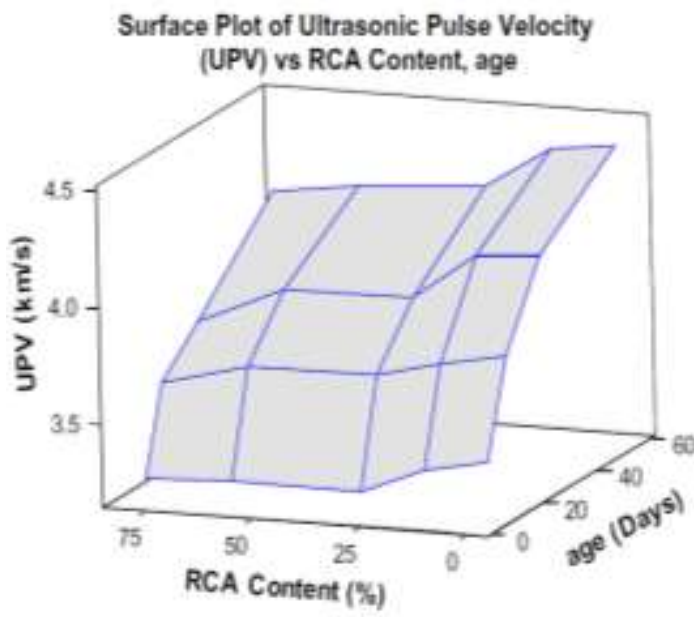

Fig. 1 Surface plot of average ultrasonic pulse velocity of specimen versus the recycled aggregate content and age [48].

Based on reported results of experimental investigation compressive test results reported that, with the increase in replacement level of the natural coarse aggregate with the recycled aggregate would reduce the compressive strength of the concrete. However, shrinkage test result reported that expansion takes place in water curing and the highest expansion attained by specimens with $80 \%$ of recycled aggregate replacement is at $64.8 \%$ compared to that of the normal concrete at 56 days. Ultrasonic pulse velocity test result reported that concrete utilizing recycled aggregate is "good" in terms of its ultrasonic pulse velocity value (figure 1).

So, It can be concluded from the study that with the increase in replacement level of recycled aggregate the compressive strength is decreasing and expansion is increasing, while its good in terms of ultrasonic pulse velocity, hence recycled aggregate can be used in production of fresh concrete but up to a certain replacement level.

4.2 Case Study II:- Influence on behavior of Concrete utilizing recycled aggregate [49].

This case study was performed to evaluate the effects of both fine and coarse recycled aggregates on the behavior of modified concrete. In this study five different mixes were prepared with a large content of recycled concrete aggregates (ranging from $27 \%$ to $63.5 \%$ of total volume of aggregates) replacing natural ones (fine and/or coarse). Bulk Density, Water Absorption, Compressive strength, Elastic Modulus, Tensile Splitting Strength, Creep \& Shrinkage test, Pore Size distribution tests were performed on prepared samples. 
Table 1:- Mix proportion of concrete utilizing recycled aggregate [49].

\begin{tabular}{|c|c|c|c|c|c|c|c|}
\hline \multirow[b]{2}{*}{ Mix } & \multicolumn{4}{|c|}{ Natural aggregate } & \multicolumn{3}{|c|}{ Recvcled aggregate } \\
\hline & $\begin{array}{l}S \\
\text { (voly) }\end{array}$ & $\begin{array}{l}\text { FG } \\
\text { (vola) }\end{array}$ & $\begin{array}{l}G \\
\text { (vol\%) }\end{array}$ & $\begin{array}{l}\text { Total } \\
\text { (vol\%) }\end{array}$ & $\begin{array}{l}R \\
16\end{array}$ & $\begin{array}{l}\mathrm{R} \\
25\end{array}$ & $\begin{array}{l}\text { Total } \\
\text { (vol } \%)\end{array}$ \\
\hline$\infty$ & 48.0 & 25.0 & 27.0 & 100 & 0.0 & 0.0 & 0.0 \\
\hline $\mathrm{RCl}$ & 48.0 & 25.0 & 0.0 & 73.0 & 0.0 & 27.0 & 27.0 \\
\hline $\mathrm{RC2}$ & 36.5 & 0.0 & 0.0 & 36.5 & 36.5 & 27.0 & 635 \\
\hline $\mathrm{RC3}$ & 36.5 & 0.0 & 27.0 & 63.0 & 36.5 & 0.0 & 365 \\
\hline $\mathrm{RC4}$ & 24.0 & 12.5 & 27.0 & 63.5 & 36.5 & 0.0 & 365 \\
\hline
\end{tabular}

As shown in table 1, RC1 were prepared replacing all the natural gravel $(G)$ with the recycled fraction $\mathrm{R} \mathrm{25.} \mathrm{A} \mathrm{further} \mathrm{concrete} \mathrm{mix,} \mathrm{named} \mathrm{RC2,}$ were prepared starting from $\mathrm{RC} 1$ and replacing half the volume of the natural aggregate fraction $0-16$ $\mathrm{mm}$ with the recycled fraction $\mathrm{R} 16$. In particular, $24 \%$ of Sand (S) and $100 \%$ of Fine Gravel (FG) were substituted with $\mathrm{R} 16$. The total volume of recycled aggregates (both $\mathrm{R} 16$ and $\mathrm{R} 25$ fractions) in $\mathrm{RC} 2$ was equal to $63.5 \%$. In order to investigate the effect of the fine aggregate substitution on the concrete properties, two further mixes were prepared keeping constant the volume as natural gravel. In more details, RC3 was prepared with the same volume as $\mathrm{R} 16$ fine recycled aggregates as $\mathrm{RC} 2$, $36.5 \%$ and $27 \%$ of natural aggregates ( $S$ and $G$ fraction, respectively). The total volume of recycled aggregates in RC3 was equal to $36.5 \%$ and corresponds to $50 \%$ of the fine fraction substitution. Finally, RC4 was prepared starting from RC3 and operating a different amount of replacement for $\mathrm{S}$ and FG. In particular, half the volume of natural sand and fine gravel was replaced with recycled aggregates.

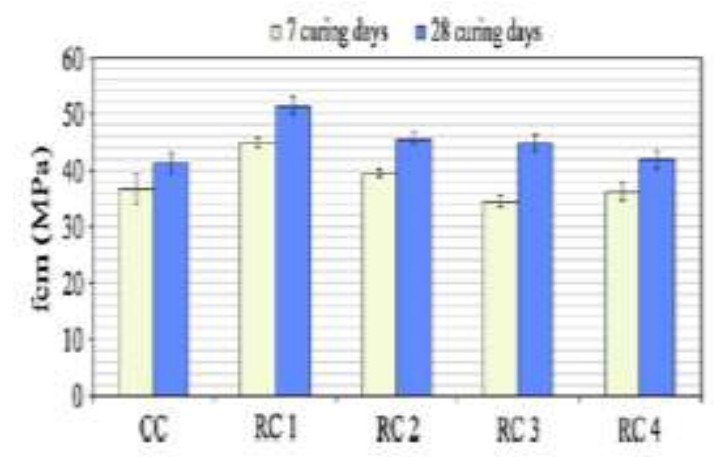

Fig. 2 Concrete compressive strength results at 7 and 28 days [49]

Based on reported results of experimental investigation, concrete workability was more influenced by the shape, texture and grain size distribution of the recycled aggregates than by their total amount. Among the investigated RACs, RC1 and RC4 exhibited the satisfactory compressive (figure 2), flexural strength, elastic modulus and the best physical features (density and water absorption), thus highlighting that a proper assortment of fine and coarse concrete waste could lead to good structural concrete as using only coarse recycled aggregates. Concrete shrinkage strain was negatively influenced by the use of recycled aggregates, whereas specific creep results showed that $\mathrm{RC} 1$ recycled aggregate concrete exhibited even better performance than the reference concrete. While it was noticed that, porosity data and pore size distribution fully agreed with the mechanical properties determined for the investigated samples, thus confirming the use of recycled concrete aggregates could lead to very dense microstructures.

So, it can be concluded that, $27 \%$ to $36.5 \%$ partial replacement improves various properties of modified concrete and can be used to prepare the concrete successfully.

4.3 Case Study III:- Comparison of properties of concrete containing normal recycled aggregate and preserved quality recycled aggregate [50].

This case study was performed to compare the concrete utilizing recycled concrete aggregate of preserved quality with concrete utilizing commercially available recycled concrete aggregate. In this study 29 mixes were tested with recycled aggregate replacement level ranging from $30 \%$ to $100 \%$ of the coarse aggregate five different mixes were prepared with a large content of recycled concrete aggregates (ranging from $27 \%$ to $63.5 \%$ of total volume of aggregates) replacing natural ones (fine and/or coarse).

A two-stage mixing procedure was followed for all mixtures tested in the study. Fresh properties were determined and to examine slump retention, slump test was carried at 15-min intervals for a total of $45 \mathrm{~min}$. Further compressive strength, splitting tensile strength test, drying shrinkage and salt scaling testing were performed to on the prepared samples.

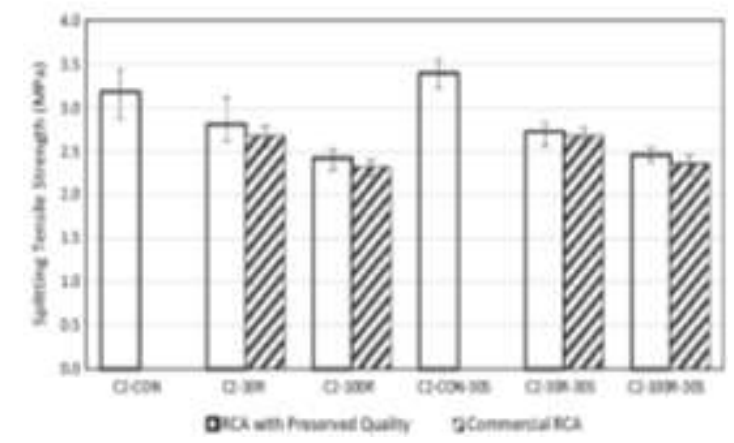

Fig. 3 Splitting tensile strength results of preserved recycled aggregate verses commercial recycled aggregate [50]. 
Based on the results of the experimental study it was reported that, recycled aggregate of preserves quality were found to have higher quality than commercially available recycled aggregate and the slump retention results showed feasibility to produce recycled aggregate concrete of adequate workability and workability retention. While increase in the amount of recycled aggregate in the mix resulted in a decrease in compressive strength. However, concrete made with preserved-quality recycled aggregate showed higher strength when compared to the same grade of concrete containing commercial recycled aggregate. The same conclusion applies to splitting tensile strength (figure 3 ). It was also reported that an increase in the amount of recycled aggregate resulted in an increase in drying shrinkage. Concrete with commercial recycled aggregate experienced significantly more shrinkage compared to concrete with preservedquality recycled aggregate.

Durability test results reported that all salt scaling concrete samples which contained the right amount of entrained air were able to satisfy the 0.8 $\mathrm{kg} / \mathrm{m}^{2}$ mass loss requirement. However, an increase in the amount of recycled aggregate increased salt scaling. Concrete with commercial recycled aggregate samples exhibited significantly more mass loss compared to concrete containing preservedquality recycled aggregate.

So, It can be concluded from this study that using preserved-quality recycled aggregate at $30 \%$ partial replacement of coarse aggregate was found to produce concrete of performance similar to that of concrete with normal recycled aggregates.

\section{CONCLUDING REMARKS}

Recycled aggregate is the material for today's modern era as it is economic and ecofriendly. Recycled aggregate posses relatively lower bulk density, crushing and impact values and higher water absorption as compared to natural aggregate. Properties of recycled aggregate as highlighted in this paper suggest that, a suitable concrete mix design will produce the recycled aggregate concrete which will achieve target strength and durability properties. The salient remark for the use of recycled aggregate as follows:

- Recycling concrete demolition waste as aggregates are a better way of reusing materials by keeping them from being disposed into landfills.

- Physical properties decrease due to coating of mortar over surface of recycled aggregate.

- The mechanical properties and durability properties also get negatively influenced if recycled aggregate is used in concrete above $30 \%$ by weight replacement.
- Utilization of recycled aggregate is cost efficient as compared to the natural aggregates, hence properly use can reduce the project cost as well as save environment.

\section{REFERENCES}

[1]. Kosmatka, S.H., Kerkhoff, B., Panarese, W.C., Macleod, N.F. \& Mcgrath, R.J. (2002). Design and control of concrete mixtures. ( $7^{\text {th }}$ ed.) Ottawa, Ontario, Canada: Cement Association of Canada.

[2]. Mehta, P. K., \& Meryman, H. (2009). Tools for reducing carbon emissions due to cement consumption. Structure, 1(1), 11-15.

[3]. Hansen, T. C. (1986). Recycled aggregates and recycled aggregate concrete second state-of-theart report developments 1945-1985. Materials and structures, 19(3), 201-246.

[4]. Rao, M. C., Bhattacharyya, S. K., \& Barai, S. V. (2011). Influence of field recycled coarse aggregate on properties of concrete. Materials and Structures, 44(1), 205-220.

[5]. Limbachiya, M., Meddah, M. S., \& Ouchagour, Y. (2012). Performance of Portland/Silica Fume Cement Concrete Produced with Recycled Concrete Aggregate. ACI Materials Journal, 109(1),91-100.

[6]. Best practice guide for the use of recycled aggregates in new concrete. Technical report TR 14, Cement \& Concrete Association of New Zealand (CCANZ) October 2011.

[7]. Hansen, T.C. (1992) Recycling of Demolished Concrete and Masonry. Oxfordshire, UK: Taylor and Francis.

[8]. Li, X. (2008). Recycling and reuse of waste concrete in China Part I. Material behaviour of recycled aggregate concrete. Resour Conserv Recycle. 53(1), 36-44.

[9]. Etxeberria, M., Vazquez, E., Mari, A., \& Barra, M. (2007). Influence of amount of recycled coarse aggregates and production process on properties of recycled aggregate concrete. $\mathrm{Cem}$ Concr Res.37(5):735-42.

[10]. Movassaghi, R. (2006). Durability of reinforced concrete incorporating recycled concrete as aggregate, MASc Thesis. Waterloo, Ontario, Canada; University of Waterloo.

[11]. Katz, A. (2003). Properties of concrete made with recycled aggregate from partially hydrated old concrete. Cem Concr Res. 33(5):703-11.

[12]. Hansen, T. C., \& Narud, H. (1983). Strength of recycled concrete made from crushed concrete coarse aggregate. Concrete International, 5(01), 79-83.

[13]. Hansen, T. C., \& Boegh, E. (1985, September). Elasticity and drying shrinkage concrete of recycled-aggregate. In Journal Proceedings, 82(5), 648-652.

[14]. Gomez-Soberon, J. M. (2002). Porosity of recycled concrete with substitution of recycled concrete aggregate: an experimental study. Cement and concrete research, 32(8), 13011311. 
[15]. Poon, C. S., Shui, Z. H., \& Lam, L. (2004). Effect of microstructure of ITZ on compressive strength of concrete prepared with recycled aggregates. Construction and Building Materials, 18(6), 461-468.

[16]. Casuccio, M., Torrijos, M. C., Giaccio, G., \& Zerbino, R. (2008). Failure mechanism of recycled aggregate concrete. Construction and Building Materials, 22(7), 1500-1506.

[17]. Soroushian, P. (2012). Strength and durability of recycled aggregate concrete containing milled glass as partial replacement for cement. Construction and Building Materials, 29, 368377.

[18]. Rahal, K. (2007). Mechanical properties of concrete with recycled coarse aggregate. Building and environment, 42(1), 407-415.

[19]. Yang, K. H., Chung, H. S., \& Ashour, A. F. (2008). Influence of Type and Replacement Level of Recycled Aggregates on Concrete Properties. ACI Mater J. 3:289-96.

[20]. De Juan, M. S., \& Gutierrez, P. A. (2004, November). Influence of recycled aggregate quality on concrete properties. In International conference on use of recycled materials in building and structures, Barcelona, Spain.

[21]. McNeil, K., \& Kang, T. H. K. (2013). Recycled concrete aggregates: A review. International Journal of Concrete Structures and Materials, 7(1), 61-69.

[22]. Rao, A. (2005). Experimental investigation on use of recycled aggregates in mortar and concrete. M Tech Thesis. Dept of Civil Eng, Indian Institute of Technology Kanpur.

[23]. Tavakoli, M., \& Soroushian, P. (1996). Drying shrinkage behavior of recycled aggregate concrete. Concrete International, 18(11), 58-61.

[24]. Building Contractors Society of Japan.(1981). Committee on disposal and reuse of construction waste.

[25]. Poon, C. S., Azhar, S., \& Kou, S. C. (2003, January). Recycled aggregates for concrete applications. In Proceeding of the Materials Science and Technology in Engineering Conference-Now, New and Next (p. 16).

[26]. Limbachiya, M. C., Leelawat, T., \& Dhir, R. K. (2000). Use of recycled concrete aggregate in high-strength concrete. Materials and structures, 33(9), 574-580.

[27]. Kou, S. C., \& Poon, C. S. (2012). Enhancing the durability properties of concrete prepared with coarse recycled aggregate. Construction and Building Materials, 35, 69-76.

[28]. Malesev, M., Radonjanin, V., \& Marinkovic, S. (2010). Recycled concrete as aggregate for structural concrete production. Sustainability, 2(5), 1204-1225.

[29]. Poon, C. S., Shui, Z. H., Lam, L., Fok, H., \& Kou, S. C. (2004). Influence of moisture states of natural and recycled aggregates on the slump and compressive strength of concrete. Cement and Concrete Research, 34(1), 31-36.
[30]. Topcu, I. B., \& Şengel, S. (2004). Properties of concretes produced with waste concrete aggregate. Cement and Concrete Research, 34(8), 1307-1312.

[31]. Padmini, A. K., Ramamurthy, K., \& Mathews, M. S. (2009). Influence of parent concrete on the properties of recycled aggregate concrete. Construction and Building Materials, 23(2), 829-836.

[32]. Tabsh, S. W., \& Abdelfatah, A. S. (2009). Influence of recycled concrete aggregates on strength properties of concrete. Construction and Building Materials, 23(2), 1163-1167.

[33]. Ridzuan, A. R. M., Diah, A. B. M., Hamir, R., \& Kamarulzaman, K. B. (2001). The influence of recycled aggregate on the early compressive strength and drying shrinkage of concrete. Structural engineering, Mechanics and Computation, 2, 1415-1422.

[34]. Bairagi, N. K., Ravande, K., \& Pareek, V. K. (1993). Behaviour of concrete with different proportions of natural and recycled aggregates. Resources, conservation and recycling, 9(1-2), 109-126.

[35]. Yaprak, H., Aruntas, H. Y., Demir, I., Simsek, O., \& Durmus, G. (2011). Effects of the fine recycled concrete aggregates on the concrete properties. International Journal of Physical Sciences, 6(10), 2455-2461.

[36]. Kumar, P. S., \& Dhinakaran, G. (2011). Effect of admixed recycled aggregate concrete on properties of fresh and hardened concrete. Journal of materials in civil engineering, 24(4), 494-498.

[37]. Topcu, I.B., \& Guncan, N. F. (1995). Using waste concrete as aggregate. Cement and Concrete Research, 25(7), 1385-1390.

[38]. Kou, S. C., Poon, C. S., \& Chan, D. (2007). Influence of fly ash as cement replacement on the properties of recycled aggregate concrete. Journal of Materials in Civil Engineering, 19(9), 709-717.

[39]. Xiao, J., Li, W., Fan, Y., \& Huang, X. (2012). An overview of study on recycled aggregate concrete in China (1996-2011). Construction and Building Materials, 31, 364-383.

[40]. Otsuki, N., Miyazato, S. I., \& Yodsudjai, W. (2003). Influence of recycled aggregate on interfacial transition zone, strength, chloride penetration and carbonation of concrete. Journal of materials in civil engineering, 15(5), 443-451.

[41]. Domingo-Cabo, A., Lázaro, C., López-Gayarre, F., Serrano-López, M. A., Serna, P., \& CastañoTabares, J. O. (2009). Creep and shrinkage of recycled aggregate concrete. Construction and Building Materials, 23(7), 2545-2553.

[42]. Salem, R. M., \& Burdette, E. G. (1998). Role of Chemical and Mineral Admixtures on the Physical Properties and Frost-Resistance of Recycled Aggre-gate Concrete. Materials Journal, 95(5), 558-563.

[43]. Butler, L., West, J. S., \& Tighe, S. L. (2013). Effect of recycled concrete coarse aggregate 
from multiple sources on the hardened properties of concrete with equivalent compressive strength. Construction and Building Materials, 47, 1292-1301.

[44]. Kheder, G. F., \& Al-Windawi, S. A. (2005). Variation in mechanical properties of natural and recycled aggregate concrete as related to the strength of their binding mortar. Materials and Structures, 38(7), 701-709.

[45]. Corinaldesi, V. (2010). Mechanical and elastic behaviour of concretes made of recycledconcrete coarse aggregates. Construction and Building Materials, 24(9), 1616-1620.

[46]. Tank Y.R., Joshi M.R., Dhameliya H.K. , "Strength Assessment of Recycled Aggregate Concrete by Ultrasonic Pulse Velocity Test" (IJSETR), 2015: 4: 4210-14.

[47]. Abdul Rahman, I., Adnan, S. H., Soejoso, M. W., Zaidi, A., \& Mujahid, A. (2011). Water permeability of recycled aggregate concrete containing new pozzolan micronised biomass silica material (Doctoral dissertation, Universiti Tun Hussein Onn Malaysia).

[48]. Kwan, W. H., Ramli, M., Kam, K. J., \& Sulieman, M. Z. (2012). Influence of the amount of recycled coarse aggregate in concrete design and durability properties. Construction and Building Materials, 26(1), 565-573.

[49]. Manzi, S., Mazzotti, C., \& Bignozzi, M. C. (2013). Short and long-term behavior of structural concrete with recycled concrete aggregate. Cement and Concrete Composites, 37, 312-318.

[50]. Andal, J., Shehata, M., \& Zacarias, P. (2016). Properties of concrete containing recycled concrete aggregate of preserved quality. Construction and Building Materials, 125, 842855. 